\title{
Baseball, Modernity, and Science Discourse in British Popular Culture, I87 I-I883
}

\author{
Daniel C. Beaver (ib) \\ Department of History, Pennsylvania State University, University Park, USA \\ Email: dxb28@psu.edu
}

\begin{abstract}
Baseball in the United Kingdom has long been considered a contradiction in terms, especially during the nineteenth century, with both the 1874 National Association Tour and the 1888 Spalding Tour viewed as financial and cultural failures in a sophisticated consumer society already dominated by cricket. This article takes a fresh look at evidence from the 1870s and 1880s in order to challenge this perspective. It presents the 1874 Tour as a transnational success, articulating shared Anglo-American assumptions about modernity, science, and social progress. This discourse informed a broad process of technology transfer involving new sources of industrial power as well as the corporal techniques of modern sport. The article also places the tour in the context of a unique historical phenomenon: the transatlantic diffusion of an early modern English game to the United Kingdom as the New York Game, a modern American sport. Previous accounts of the tour focused on a few selected reports, confirming American views of its financial failings and British disinterest in its exhibitions. When considered in light of hundreds of British accounts from the 1870s, including unexamined evidence of the first British baseball clubs less than two years after the tour, this perspective becomes unsustainable.
\end{abstract}

Few historical tropes can claim the persistence of the inter-relationship between nationalism and modern sport. If early observers and later historians have differed in their interpretations of its meaning and explanations of its causes, both recognize a standardization of culture as a defining feature of modern national communities, with the codification and rationalization of modern sport as one of its significant expressions. Standardized social units and forms, exemplified in Britain after 1841 by the census, measured the nation and denoted the scale of modern society. Printed rules existed for cricket by the 1740s and for the New York Game, the earliest variant of modern

(C) The Author(s), 2021. Published by Cambridge University Press. This is an Open Access article, distributed under the terms of the Creative Commons Attribution licence (http://creativecommons.org/licenses/by/4.0/), which permits unrestricted re-use, distribution and reproduction, provided the original article is properly cited. 
baseball, by the 1850s - the rationalized basis of modern sport as a mass entertainment, a feature of standardized culture distinct from traditional games. ${ }^{1}$ During the late nineteenth century, nationalist discourse insisted on the interrelationship of national identity and experience, either through participation or observation, of the athletic performances felt to articulate fundamental qualities of national community. ${ }^{2}$ Moreover, a nationalist emphasis has dominated the study of baseball and cricket, in particular, during the late nineteenth and early twentieth centuries, their insular histories a reflection of popular cultures suffused with British imperialism and early American nationalism. In this context, American baseball tourism in Britain during 1874 and 1889 have become predictable failures, confirmations of modern sport's fin de siècle nationalist logic and symbolism, marked by a fatal absence of support or even interest in British newspapers, a key discursive element in the 'imagination' of national communities. ${ }^{3}$

While acknowledging this important dynamic, its limitations leave important problems and evidence unaddressed, not least the diffusion of the New York Game to Cuba during the 1860s and to Japan during the 1870s in the midst of the National Pastime movement in the United States, one of the key nationalist projects of the Reconstruction era. ${ }^{4}$ The nationalist meanings grafted on modern

\footnotetext{
${ }^{1}$ Amidst a voluminous historical dialogue on nationalism, for the importance of a standardized, homogeneous culture as a condition of national identity and modernity, with its implications for modern sport as an expression of culture, see Ernest Gellner, Nations and nationalism (2nd edn, Ithaca, NY, 2006), pp. 38-9, 46-8, 53-5, 89-92, 113; Benedict Anderson, Imagined communities (2nd edn, New York, NY, 1991), pp. 37-50, 53-63, 67-82, 163-85; Liah Greenfeld, Nationalism (Cambridge, MA, 1992), pp. 3, 7, 20-1, 53-4, 80-6, 148-9, 235-47, 293-302, 461-7; Johan Huizinga, Homo Ludens (Boston, MA, 1950; orig. edn 1944), pp. 195-211; Norbert Elias and Eric Dunning, eds., Quest for excitement (Oxford, 1986), pp. 3-5, 13-17, 40-62, 128-46, 152-6, 205-44; Allen Guttmann, Games and empires (New York, NY, 1994), pp. 1-11, 171-88; David Underdown, Start of play (London, 2000), pp. 2, 63-73, 95-6, 158; Wendy James, The ceremonial animal (Oxford, 2003), pp. 239-44.

${ }^{2}$ See, for example, John Walsh, ed., Encyclopedia of rural sports (8th edn, Philadelphia, PA, 1874), pp. 559, 581; Albert Spalding, America's national game (New York, NY, 1911), pp. 175-84.

${ }^{3}$ Anderson, Communities, pp. 37-46, on the importance of print language and capitalism. The themes of financial and cultural failure, defined in terms of baseball's failure to supplant cricket in Britain and understood as resulting from the political dynamics of British imperialism and American nationalism, date from the 1870s and persist in the present. See Harry Palmer, Athletic sports in America, England, and Australia (New York, NY, 1889), p. 50; Arthur Bartlett, Baseball and Mr. Spalding (New York, NY, 1951), pp. 56-71; Daniel Bloyce, “'Just not cricket”: baseball in England, 1874-1900', International Journal of the History of Sport (IJHS), 14 (1997), pp. 208-9, 21216; Daniel Boyce, 'That's your way of playing rounders, isn't it? The response of the English press to American baseball tours to England, 1874-1924', Sporting Traditions, 22 (2005), pp. 82-4; Andrew Horrall, Popular culture in London (Manchester, 2001), p. 108; William Ryczek, Blackguards and Red Stockings (2nd edn, Jefferson, NC, 2016), pp. 142-53, 163-72. See also Boria Majumdar and Sean Brown, 'Why baseball, why cricket? Differing nationalisms, differing challenges', IJHS, 24 (2007), pp. 140, 143-4, 151, for the nationalist meanings of baseball in American culture during the late nineteenth century.

${ }^{4}$ See Louis Perez, 'Between baseball and bullfighting: the quest for nationality in Cuba, 18681898', Journal of American History, 81 (1994), pp. 493-517; Roberto Echevarria, The pride of Havana (Cambridge, MA, 1999), pp. 75-111; Donald Roden, 'Baseball and the quest for national dignity in Meiji Japan', American Historical Review, 85 (1980), pp. 511-34; Robert Whiting, You gotta have wa
} 
sport did not limit its power to cross political borders. As a multivalent symbol in new mass cultures, sport assumed many meanings, its ceremony and spectacle expressing transnational as well as national significance. Indeed, the varieties of nationalism comprised several discourses easily translated from one cultural setting to another. Among these transnational discourses, those related to the nature of modernity, the value of science, and the benchmarks of progress endowed the sporting subculture with a power to signify a set of shared assumptions, transferrable skills, and, in the Anglo-American context, a common language in which competitive jargon articulated social values. ${ }^{5}$

British experience of the New York Game during the 1870s illustrates this dynamic, as newspapers and other forms of public evidence attest to baseball's significance in a broader process of Anglo-American technology transfer. In 1874, American and British athletes demonstrated modern 'field science' to the British public in a series of cricket and baseball exhibitions. During the ensuing months and years, a public debate over the demonstration's scientific merits occupied the margins of this transnational exchange involving new sources of industrial power and deliberations over their practical application. ${ }^{6}$ When examined in a local setting, this transnational discourse demonstrably informed the experience of new mechanical and performance technologies, with a significant impact on civic culture and community, political trust and sense of belonging, and forms of social identity. In Leicester, a Midlands market town that became an industrial city between 1850 and 1900, a range of evidence indicates how and why the discourses of modernity, science, and progress related to the practical uses of electricity during the 1870 s and early 1880 s furnished the transatlantic context for the local organization of Britain's first baseball clubs, only eighteen months after the 1874 American Tour. Leicestrians adopted the New York Game in response to its transnational meanings - its modernity, its scientific discipline, its progressive, civilizing qualities - which were debated in British newspapers during the 1870s. The experiences of individuals, families, and neighbourhoods in Leicester suggest the importance of transnational cultural influences for identities usually understood in national terms. In a similar way, the New York Game's small scale as a niche seasonal pastime in Britain during the late nineteenth and early twentieth centuries have made it largely invisible in national histories. As Leicestrian experience indicates, small scale belied its value in local navigation of the major demographic and social changes of the late nineteenth century.

(New York, NY, 1989), pp. 27-39; Thomas Zeiler, Ambassadors in pinstripes (Lanham, MD, 2006), pp. 1-72; Ryan Swanson, When baseball went white (Lincoln, NB, 2014).

${ }^{5}$ James, Ceremonial, pp. 243-4. See Gellner, Nations, pp. 110-17, for a theoretical sketch of 'industrial culture' that frames this transnational discourse without describing it.

${ }^{6}$ This refers to an Anglo-American discourse on 'thinking and writing electricity' during the 1800 s and to complex transatlantic issues surrounding electrification during the 1870 s and 1880s. See Thomas Hughes, Networks of power (Baltimore, MD, 1983), pp. 47-78; Graeme Gooday, The morals of measurement (Cambridge, 2004), pp. 176, 186, 220-1, 222-5, 232, 234, 238, 240-1; Sam Halliday, Science and technology in the age of Hawthorne, Melville, Twain, and James (New York, NY, 2007), pp. 1-15; Paul Gilmore, Aesthetic materialism (Stanford, CA, 2009), pp. 10-15, 19-110, for the tropes, technology, and politics of this discourse and the practical uses of electrical power in the United States and Great Britain. 
Before charting the New York Game's transatlantic diffusion between 1871 and 1876, an influential Leicester company serves as a synecdoche of the Anglo-American technical transfer of which it formed part. Nathaniel Corah, Sons, and Cooper, manufacturers of hosiery and footwear in a factory complex that ranked on a European scale, sponsored several local athletic societies during the 1870s, fielded a cricket club in the competitive local arena, and also organized one of the first four baseball clubs in 1876 during the New York Game's inaugural season in Leicester. In 1883, amid civic celebration and commemoration, the firm introduced the first electrification in its expanded factory, styled St Margaret's Works. The discursive tropes that explained the meanings of these transnational innovations used many of the same terms and metaphors. Both the New York Game and workplace illumination involved the controlled use of force, as 'the force of electricity had been overcome and subdued for practical purposes' in a way comparable to the techniques of marshalling force in co-ordinated 'relays' on Leicester's public fields. Both innovations expressed American techniques through British hands. St Margaret's Works featured the technological achievements of the Brush Electric Light Company, a joint American and British venture: one of Charles Brush's dynamos and fourteen of his arc lamps 'in the warehouses and finishing rooms', and eighteen of Joseph Swan's incandescent lamps 'in the offices and private rooms'. In tropes regularly used in 1874 to describe distinctive features of the New York Game, Bernard Drake, the Brush Company's electrical engineer, emphasized the system's speed in co-ordinating the new sources of power with the steam-driven technology of the factory. Principles of energy conservation figured in both settings, as 'field science' intersected the new natural philosophy, and the 'science of converting electricity' evoked profound questions of the life force itself. Nor were these disembodied abstractions, for 'yesterday we [saw] evidences of its utility in the large manufactory of Nathaniel Corah, Sons, and Cooper, St. Margaret's Works, Leicester'. Under the leadership of this socially activist firm, experience of the new mechanical and corporal technologies promoted a felt connection between the disciplined use of energy and the principles of individual improvement and collective progress. When the newspapers celebrated the immense establishment, where over a thousand hands are employed', for having 'taken hold of this illuminating agent, and made it subservient to their desires', with the 'conspicuous energy which has marked the progress of this firm for a century', they merely highlighted this multivalent transnational process, the easy translation of American techniques in a local British setting. The 'beneficence of brilliant light' crossed political borders as readily as a modern sport designed to fit an afternoon's release from work. In Leicester, the meanings of both partly reflected the entrepreneurial illumination of Nathaniel Corah, Sons, and Cooper-a node of transnational transfer - achieved more than a decade before Leicester corporation first delivered electric power to the central business and commercial district in $1894{ }^{7}$

\footnotetext{
${ }^{7}$ Leicester Daily Post (LDP), 5 Dec. 1876, p. 4; Leicester Chronicle and Leicestershire Mercury (LCLM), 6 Jan. 1883, p. 6; 'Bernard Drake', Page's Weekly, 5 (1904), p. 857; Proceedings of the Institution of Electrical
} 


\section{II}

In its transatlantic diffusion, the New York Game appeared in the United Kingdom first in printed form. Britons read about and observed the game for at least three years before small numbers began to play it in 1874. The New York Game arrived in London on 21 January 1871, when an issue of Sporting Life printed a description of 'base ball' alongside a diagram of the New York Game's field pattern. In tone and tropes, the Sporting Life treatment encouraged readers to see in the New York Game not a foreign import but a prodigal returned. Although 'few Englishmen know what Base Ball really is... [i]t is simply the old sport of rounders, reduced to a scientific basis'.

The reporter's use of the term 'scientific' helps to illuminate the value of 'field science' as a vector for the introduction of science discourse in popular culture, at the same time rendering baseball and cricket as related expressions of a common discipline. In one sense, 'scientific rounders' described a technique, the use of 'bats...round, like a policeman's truncheon', to 'drive' a ball 'similar [in size] to a tennis ball', which 'when struck with the bat', moves 'with ten times the velocity of a cricket ball...it [being] no uncommon thing for players to have a finger broken when trying to stop a ball'. Its technique affected baseball's unique physics, 'for a ball driven straight from the bat at cricket has...little twist on it...[b]ut a ball struck by a base-ball club...has a tremendous amount of twist, and...even if a ball is driven right into a man's hands, it is more liable to work out again than at cricket'. As a result, 'scientific rounders' involved a complex technique in its art of fielding the ball in motion and throwing accurately to bases, but its combination of techniques and limited innings introduced the 'arbitrary nature of the game', identified in American newspapers as early as 1845 and appreciated by the British reporter as its 'variety in chances at different stages of the game'. In this second sense, 'science' meant the elimination of chance, the technique of 'the steady-going cricketer' and the achievement of cricket as 'a game without chance, a game of science'. Introduced thus, baseball and cricket shared such common scientific challenges as the control of variation and the management of risk, assessing the quality of athletic performance in terms of a statistically measured efficiency in meeting these challenges, and many techniques translated easily from one to the other. ${ }^{9}$

The first recorded exhibition of the New York Game in the United Kingdom occurred six months later on 13 June 1871, at the Bat and Ball Cricket Ground in Gravesend. An account of 'a game of base ball' between the Blue Shirts and the White Shirts from the crew of the USS Franklin appeared in The Gravesend and Dartford Reporter, including a box score, a sketch of the field order identifying it as the New York style, and observations on its dynamics intended to confirm its familiarity to British readers. ${ }^{10}$ The reporter echoed a major theme of Sporting Life, folding the contest into British experience as 'an

Engineers, 60 (1922), pp. 435-8; R. McKinley, ed., History of the county of Leicester, IV (London, 1958) (VCH Leicester), pp. 275-94.

${ }^{8}$ Sporting Life (SL) (London), 21 Jan. 1871, p. 4.

${ }^{9}$ Ibid. See also New York Morning News, 22 Oct. 1845.

${ }^{10}$ Gravesend and Dartford Reporter, 17 June 1871, p. 4. 
elaboration of the well-known game of "rounders", played by eighteen persons, nine each side'. It required special equipment, for the ball was hit using 'a club about three feet long, with which the players appeared remarkably skillful'. Like cricket, it divided the field and allocated the forces of the game in terms of a specialist jargon, 'as the field is apportioned to pitcher, catcher, 1st, 2nd, and 3rd bases, short stop, centre field, right field, and left field', the spatial pattern of the New York Game. Although the British perspective rendered the New York Game in its own verbal idiom, the box score translated the action on the field into numeric stories of victory and defeat that newspapers had made familiar to Americans and Britons alike during the second half of the nineteenth century. The result offered a mathematical table of success and failure for each individual as well as their teams. ${ }^{11}$ If baseball's dynamics, especially its alternation of sides during innings, required contextualization for British readers, this moral and competitive calculus, the use of tables and statistics to measure production and to demonstrate value, translated American baseball's ethos and scientific discipline into a journalistic idiom used daily in British newspapers. The significance of this first encounter lies in its appreciative recognition of 'a game of base ball' as nothing less than an American variant of the familiar modern field science expressed in sport. ${ }^{12}$

\section{III}

These tropes of familiarity and appreciation recurred in 1874, when American professional teams toured the United Kingdom during July and August, offering various baseball demonstrations in addition to exhibition games and participating in cricket matches as part of a reciprocal engagement with their British hosts. As early as 2 February 1874, The South Wales Daily News printed a notice observing public 'interest' in the project, introducing Albert Spalding as 'the pitcher of the Boston Base-Ball Club', who had 'left America for England to make preparations for the reception of his brethren', and identifying 'the Boston Base-Ball Club and the Athletic Base-Ball Club of Philadelphia' as the tourists expected in late July. Other regional newspapers printed the notice, promoting the tour on a national scale before the end of the month. ${ }^{13}$ In the absence of details, the British press showcased the tour as a transatlantic demonstration of both baseball and cricket, announcing that the Marylebone Cricket Club (MCC), the regulatory authority of British cricket, had agreed to assist 'the project for a series of American base-ball and cricket matches in London'. ${ }^{14}$ Indeed, Bell's Sporting Chronicle confidently

\footnotetext{
${ }^{11}$ In a manner similar to the British baseball clubs that formed later in the decade, the Franklin clubs brought together a diverse group of individuals for organized play, including landsmen and seamen, a blacksmith and a cooper as well as 'mariners'. See United States, Naval enlistment rendezvous, 1855-1891, vol. 57, pp. 316, 330, vol. 58, pp. 30, 38.

${ }^{12}$ Gravesend and Dartford Reporter, 17 June 1871, p. 4.

${ }^{13}$ South Wales Daily News (Cardiff), 2 Feb. 1874, p. 4; Hull Packet, 6 Feb. 1874, p. 3; Cambridgeshire Times, 7 Feb. 1874, p. 7; LDP, 18 Feb. 1874, p. 2; Merthyr Telegraph (MT), 20 Feb. 1874, p. 4.

${ }^{14}$ LDP, 18 Feb. 1874, p. 2; MT, 20 Feb. 1874, p. 4; SL, 21 Feb. 1874, p. 3. Ultimately, the tour relied on the cricket experience of Harry and George Wright, adding only the Wrights' younger brother
} 
stated that 'most of the best cricketers in America are also the leading baseball players', finding 'much pleasure' in the proposal 'to play both games', and adding that, because 'a base-ball match averages two hours...it would be no difficult matter for our visitors to show us how they can wield the willow on the other side of the Atlantic'. ${ }^{15}$

Whatever the designs of Harry Wright and Albert Spalding, the tour's British organizers understood it as a joint exercise to showcase cricket and baseball as common exemplars of the new modern field science, a civilizing force that transcended nationalist political discourse as easily as it crossed national borders. The transatlantic social networks involved in its organization express this transnational idiom as fluently and publicly as the newspaper promotions of its objectives. In a published letter, Harry Wright thanked the officers of St George's Cricket Club - composed of British expatriates like himself in late February, 1874, 'for the favors shown me in furnishing Mr. Spalding with letters of introduction to gentlemen in London, which I hear have been of great service to him'. ${ }^{16}$ In response, Robert Fitzgerald, MCC secretary, 'proffered us the use of Lord's Ground for our first game at but light expense'. An earlier letter from Spalding, published in the same issue of Forest and Stream, described his introduction to Charles Alcock, Surrey Cricket Club secretary and the London Sportsman's cricket editor, as well as officers of the [London] Amateur Athletic Club, who framed the project in transnational terms, 'advis [ing] a tour of the three sections of Great Britain, finishing at Dublin'. ${ }^{17}$ Alcock, whose support made available the Surrey Club's ground at Kennington Oval, also agreed to handle the details of the match schedule and promotions. ${ }^{18}$ Before departing on 15 March, Spalding and his travelling companion Warren Briggs, a catcher at Harvard and a director of the amateur Beacons Baseball Club in Boston, sealed these new relationships in the first transnational demonstration of the New York Game at the Kennington Oval on 27 February. ${ }^{19}$ In a match that confirmed the interchangeability of techniques in field science, Charles Alcock outpitched Spalding in a 17 to 5, six-inning victory, as Briggs formed a battery with Alcock while Spalding pitched to

Samuel to augment the tour's cricketing skills. See Forest and Stream (FS) (New York), 5 Mar. 1874, p. 7; Palmer, Sports, pp. 48-9. These decisions may reflect the American organizers' use of the tour to test the superior utility of baseball's technical or 'scientific' skills against the demands of cricket. See Tom Melville, The tented field (Bowling Green, OH, 1998), pp. 62-3.

${ }^{15}$ Bell's Life in London and Sporting Chronicle (BLLSC), 14 Feb. 1874, p. 4, importing the rhetoric common in American newpapers during Reconstruction, describing baseball as the 'national game' in the 'land of Stars and Stripes'. See Swanson, Baseball, p. 19.

${ }^{16}$ Harry Wright to Charles Vinten, treasurer, St George's Cricket Club, published in FS, 5 Mar. 1874, p. 7.

${ }^{17}$ Albert Spalding to (Philadelphia publisher) Joshua Lippincott, in FS, 5 Mar. 1874, p. 7.

${ }^{18}$ Illustrated Sporting and Dramatic News (ISDN), 21 Mar. 1874, p. 9; LDP, 21 Mar. 1874, p. 7; Preston Herald, 28 Mar. 1874, p. 7. An early draft indicates that Wright and the other American organizers expected to play six cricket matches to fifteen baseball games, a ratio close to the seven and fourteen played during the tour. See New York Clipper, 7 Mar. 1874, p. 3.

${ }^{19}$ Boston Globe, 2 Apr. 1874, p. 8; The National Archives, US, Records of US Customs Service, Passenger lists of vessels arriving at Boston, RG 36, Series M277, Roll 87, Hecla: 16 Mar. 1874; BLLSC, 4 Apr. 1874 , p. 5. 
Edward Poole, an All England wicket keeper, leading nines comprised of British cricketers and football players. ${ }^{20}$

British promotion and reception of the National Association 1874 Tour of the United Kingdom reflected these transnational understandings of its meaning. ${ }^{21}$ As early as 23 May, The Daily Telegraph touted the project as 'one of the most striking features of the cricket year', and Britons looked forward to a mix of cricket and 'practical illustrations' of the New York Game, with the 'result of popularising among us another scientific outdoor game'. ${ }^{22}$ Precisely how baseball would fit in the British outdoor regimen remained open to speculation. Perhaps it could relieve 'the dull season that twice a year occurs when cricket and football are in disuse', and even the sceptical Daily Telegraph opined that a 'rushing, helter-skelter game, as we understand base-ball', could 'at least rank in public estimation here with lawn tennis and racquets among University men, and [with] bat, trap, ball, and rounders among our villagers and schoolboys'. ${ }^{23}$

However, a dominant theme in this discourse involved the parallels and interchangeability of skills between cricket and baseball. A plurality of British newspapers described baseball in proprietary terms as 'akin to cricket'. A major distinction involved baseball's speed, an aspect of its 'laws' and game flow that reduced its 'scientific' potential relative to cricket by allowing greater influence to chance. In July, The Sheffield Daily Telegraph introduced readers to baseball as a 'fast game, requiring great activity, of unflagging interest, and, even more than cricket, gloriously uncertain'. ${ }^{24}$ Another trope in this British domestication of the New York Game reprised the early 1870s reports, describing baseball as 'scientific rounders'. ${ }^{25}$ Indeed, this trope could signal a general philosophical attempt to make sense of modern sports as evolutions or 'scientific adaptations' of 'simpler [British] games'. Along these lines, The York Herald mused on the New York Game's relationship to rounders as analogous to cricket's relationship to 'cat and dog', a northern British bat and ball game. In Dublin, the Freeman's Journal observed that 'old games under new titles are

\footnotetext{
${ }^{20}$ Palmer, Sports, pp. $47-8$.

${ }^{21}$ Much of the research on the tour reflects the American perspective. Albert Spalding's memoir channels his engagement in the American nationalist discourse of the late nineteenth and early twentieth centuries. See Spalding, National game, pp. 175-84; Bartlett, Baseball, pp. 56-71; Ryczek, Blackguards, pp. 142-53, 163-72.

${ }^{22}$ Daily Telegraph and Courier (DTC) (London), 23 May 1874, p. 8; SL, 18 July 1874, p. 4 (promoting the American baseball players as 'including some really good cricketers'). See also DTC, 21 July 1874 , p. 6; London Evening Standard (LES), 29 July 1874, p. 3; Sheffield Independent (SI), 29 July 1874, p. 4; Chelmsford Chronicle, 31 July 1874, p. 7, for British expectations; and DTC, 21 July 1874, p. 6; Manchester Evening News (MEN), 25 July 1874, p. 3, for 'popularising' a 'scientific game'.

${ }^{23}$ Exeter Flying Post, 29 Apr. 1874, p. 8; York Herald (YH), 15 July 1874, p. 7; DTC, 21 July 1874, p. 6; ISDN, 25 July 1874, p. 6. After 1874, baseball did tend to attract British men in their late teens and early twenties.

${ }^{24}$ On this status of baseball as 'akin' to cricket, see ISDN, 18 July 1874, pp. 10, 13; Sheffield Daily Telegraph (SDT), 28 July 1874, p. 6; SI, 29 July 1874, p. 4; Birmingham Daily Post, 30 July 1874, p. 4; Bradford Observer (BO), 30 July 1874, p. 7; Freeman's Journal (FJ) (Dublin), 30 July 1874, p. 3; YH, 31 July 1874, p. 8; Warwick and Warwickshire Advertiser, 1 Aug. 1874, p. 3.

${ }^{25}$ DTC, 30 July 1874 , p. 2 ; YH, 15 July 1874 , p. 7.
} 
becoming a characteristic of our time', describing the New York Game as 'a modification of the pastime known as prison base or prison bar', an English running and chasing game. ${ }^{26}$ That such observations were fictions does not lessen their value as evidence of belief in modern sports as 'scientific' evolutions from simpler forms of play.

Moreover, this discourse of 'scientific adaptation' acquired added significance as the transnational dividend of an emerging transatlantic infrastructure that made the tour possible and became inseparable from its meaning. The power to move two professional sports clubs and their entourage more than three thousand miles across the ocean, at a speed that enabled successful exhibitions without compromising the integrity of the professional season, reflected decades of competition between American and British entrepreneurs to encompass the commercial potential of the Atlantic. Since the late $1840 \mathrm{~s}$ and 1850s, when Samuel Cunard and Edward Collins had embodied this national rivalry, the Cunard Line and the Collins Line had vied to set the record for the fastest Atlantic crossing. ${ }^{27}$ However, in a pattern that would also inform the diffusion of the New York Game and electrical technology during the 1870s and early 1880s, this Anglo-American competition for speed in the Atlantic involved an important transnational dimension. The major lines often depended on the financial support of such transatlantic companies as Brown, Shipley, and Brown Brothers, politically connected merchant bankers in Liverpool, London, and New York, who helped to mobilize the international capital required to build the Collins Line's first four Atlantic steamships in $1849 .^{28}$ These used a common iron and steam technology that from the 1850s symbolized the cutting edge of Atlantic commerce, especially its communications network, where steam earned its state subsidies in the transatlantic mail service. ${ }^{29}$ Underlying fiscal and technical commonalities, the competition expressed shared Anglo-American beliefs about the inter-relationship of technology, social progress, and civilization. By the late 1860s, this transnational synergy fostered dreams of a socially inclusive and commercially lucrative 'transatlantic ferry', which would 'greatly promote comfort and speed at sea' by combining the new efficiencies of steam technology in compound engines and screw propellers with the civility and social order of 'hotels' and 'respectable restaurants in London or New York'. ${ }^{30}$

The 1874 National Association Tour travelled on the American Line, which had recently emerged from the Pennsylvania Railroad Company to connect the ports of Philadelphia and Liverpool. The American Steamship Company's first

${ }^{26}$ YH, 15 July 1874, p. 7; FJ, 29 July 1874, p. 7; Alfred Story, 'The evolution of cricket', Strand, 10 (1895), pp. 321-8. See David Block, Baseball before we knew it (Lincoln, NB, 2005), pp. 23, 122-3, for Henry Chadwick's mistaken view of prisoner's base as an antecedent of rounders and the New York Game.

${ }^{27}$ William Fowler, Steam titans (New York, NY, 2017), pp. 149-68.

${ }^{28}$ Ibid. See also J. Killick, 'Sir William Brown (1784-1864)', in ODNB.

${ }^{29}$ See Gerald Graham, 'The ascendancy of the sailing ship, 1850-1885', Economic History Review, new series, 9 (1956), pp. 74-88, for the persistence of sailpower during the second half of the nineteenth century.

30 'A transatlantic ferry', Anglo-American Times, 5 May 1866, pp. 2-3. 
four ships-the Pennsylvania, Ohio, Indiana, and Illinois-advertised the Pennsylvania Railroad Company's main line from Philadelphia to Chicago just as their compound engines - among the first built in the United States promoted the futuristic ease of transatlantic travel in newspaper accounts of the Americans' arrival in Britain. ${ }^{31}$ Although the Ohio's eleven-day Atlantic crossing from Philadelphia to Liverpool between 16 and 27 July did not break records, it situated the tour in this dynamic sphere of transnational change. Just as new steam technology facilitated the arrival of the New York Game, it also carried the agents of international trade and communication among its 400 passengers. An entourage estimated at between forty and sixty 'enthusiastic admirers of the game...including several ladies' accompanied the players, 'and for their convenience Mr. [George] Pullman, who is in England superintending the running of his cars on the Midland Railway, has placed his carriages at their disposal'. The Midland Railway Company magnified this gesture by 'generously [assigning] a special train' for the journey from Manchester to London. ${ }^{32}$ The camp followers included 'gentlemen engaged in mercantile pursuits' as well as 'representatives from some of the American papers.. ${ }^{33}$ Through media accounts of its oceanic travel and human agents, the transnational movement of 'field science' thus mirrored a broader circulation of ideas, technologies, and commodities informing a progressive, civilizing international order. ${ }^{34}$

Among this project's transnational achievements, it definitively introduced the New York Game in Britain as a unique variant of modern field science. More than any other journalistic source, Charles Alcock's contributions to the London publications, Illustrated Sporting and Dramatic News and The Field, synthesized the elements of British reception since 1871. Under the pseudonym 'Cosmo', Alcock's 'Base-Ball, the American Game' offered a transnational or 'cosmopolitan' perspective on baseball's significance in the international arena of scientific field exercise, first published in The Field but reprinted in the editor's popular Encyclopedia of rural sports and excerpted in the influential American journal Forest and Stream. ${ }^{35}$ Drawing on the authority of a forum that

\footnotetext{
${ }^{31}$ William Flayhart, The American Line (New York, NY, 2000), pp. 15, 20-4, 53; Emory Edwards, Modern American marine engines, boilers, and screw propellers (Philadelphia, PA, 1881), pp. 101-3.

${ }^{32}$ This composite draws from accounts of the tour in ISDN, 18 July 1874, p. 10; Bradford Daily Telegraph, 23 July 1874, p. 2; MEN, 28 July 1874, p. 4; Irish Times (Dublin), 29 July 1874, p. 5; LES, 29 July 1874, p. 3; SL, 29 July 1874, p. 1; BO, 30 July 1874, p. 7; Essex Standard, 31 July 1874, p. 8; YH, 31 July 1874, p. 8; Oxford Journal, 1 Aug. 1874, p. 8; Sporting Times (London), 1 Aug. 1874, p. 5; Sportsman (London), 1 Aug. 1874, p. 8; Scotsman (Edinburgh), 3 Aug. 1874, p. 6; Manchester Courier and Lancashire General Advertiser (MCLGA), 3 Aug. 1874, p. 8.

${ }^{33}$ The entourage included Joseph Rockhill, William Milligan, and Charles Cragin, subsequently 'leading merchants of Philadelphia', and George Taylor, 'the largest US tin importer', among others. Alfred Wright, later the Clipper's baseball editor, reported for Philadelphia's Sunday Mercury, Herbert Kempton for the Boston Herald. Palmer, Sports, p. 48.

${ }^{34}$ This synergy of tourist infrastructure and technical field sport also helped to promote Spalding's world tour in 1888. Zeiler, Ambassadors, pp. 20-5.

${ }^{35}$ ISDN, 18 July 1874, 10, 13; Field (London), vol. 44, 25 July 1874, p. 100; FS (New York, Philadelphia, Chicago), vol. 3, 13 Aug. 1874, p. 13; Walsh, ed., Encyclopedia, pp. 581-811. Walsh edited The Field and Encyclopedia, presented as a 'scientific' manual of rural pastimes.
} 
routinely reported innovations in animal breeding and ballistics, Alcock adjudged the New York Game as 'scientific' and 'more difficult' to play than its 'outward semblance', presenting it to the British public as an unseen complexity and challenge of pattern recognition for the aficionados of field sports. Comparing its evolution to cricket, its changes resulted from the scientific impact of experience on its organized play - the 'yearly recourse to improvements necessitated by the experiences of each season' reflecting the experimental ethos that made baseball 'the cricket of the American continent'. As expressions of modern field science, baseball and cricket afforded 'full scope for the exercise of those mental as well as physical attributes which mark the intelligent and cultured athlete', a capacity to invigorate and sustain the cultural as well as the physical attributes of a people - the capital essential to a muscular civilizing power. As a result, the model baseball player, like the cricketer, required 'great judgment' as well as 'endurance and nerve', though the game also embraced equal merit in the sense that 'anyone' with these attributes 'can attain a certain perfection in the game' through 'constant practice' and 'strict training'.

Alcock's insight lay in his appreciation of the New York Game's unique physics and game flow, qualities that justified a separate place in the annual cycle of field exercise. He explained its science by comparison to the "wearisome monotony...at times...in the cricket field', with this controlled repetition replaced in baseball by multiple changing scenarios, one scene dissolving into another, 'the fluctuations rapid, and the uncertainties almost as marked as in cricket'. Like cricket, baseball's field geometry defined its unique physics and the physical challenges offered to players. 'The pitcher is confined to ground six feet square', its 'front line' forty-five feet 'from the centre of home base'. The 'batsman's ground' in the 'infield' is 'limited to a space three feet by six feet...divided by the line of home base'. The positions of the 'fieldsmen' further constrained the physics in play. Otherwise, 'as at cricket', the pitcher may 'vary...his bowling to deceive the batsman', and 'a good pitcher and catcher in accord...can...get rid of even a strong batting side'. Alcock recognized the centrality of this 'battery' of pitcher and catcher, and how mastery of this aspect of the physics enabled two players, working together, to dominate nine on the other side. He then explained the complex 'laws' devised 'to curtail the liberties of the bat' and the dynamics of 'force' that governed the running of bases.

Alcock intended this 'comprehensive description' of the New York Game 'to make the object and details understood by Englishmen', not to set up a competition between baseball and cricket for British loyalties. In pursuit of this transnational goal, he stressed its didactic qualities, its civilizing virtues, and therefore its fitness and scientific claim for inclusion in the British repertoire. To play required 'judgement, courage, presence of mind, possession of much the same qualities' as cricket. Indeed, observing expert play 'will astonish those who only know it by written description, for it is a fast game, full of change and excitement'. To see 'the best players field' was 'a sight to do a cricketer's heart good, the agility and accuracy of timing and catching by the Americans being wonderful'. Alcock's conclusion struck this modern chord 
of observation and the improved experience of crowds. The didactic, civilizing influence of the New York Game, as in cricket, worked through observation as well as participation. In terms of ludic diffusion, The Field's authority as well as the essay's perspective on the 'science' of the New York Game countered the several newspaper accounts that rejected it, identifying them as expressions of a false dichotomy, based on an 'unscientific', sentimental affection for cricket. $^{36}$

\section{IV}

Although like other evidence of modern mass media the impact of this transnational science discourse remains difficult to measure, British newspapers did express concerted interest in the British public's attitudes and responses to the 1874 National Association Tour, and the resulting record of the tour's reception reveals a pattern of expectations met and exceeded. If the standard is defined in terms of this transnational understanding of the New York Game as a legitimate expression of modern field science, many of its techniques familiar from the British experience of its simpler antecedents, and a valuable addition to the British seasonal repertoire - in other words, assessed in terms of its meaning for British promoters - the reported responses to its fourteen baseball games and seven cricket matches suggest a successful process of ludic diffusion, especially in light of the evidence of baseball clubs forming in Britain during the months and years following the tour. ${ }^{37}$

Among reported responses, the most consistent surfaced immediately after the first game on 30 July at the Liverpool Cricket Club's Edgehill ground. During the ensuing month of contests, British observers identified 'the spirit of the game' in its 'splendid fielding...so brilliant [from the fourth through the seventh innings] that there was no chance of runs', a display of skill which 'met its recognition in hearty applause'. ${ }^{38}$ A distinctive feature of the field experiment involved the value of precise fielding in an 'inning' arbitrarily limited to three outs - the limits imposed by rule on the science and force of batting evoking this countervailing defensive science, with its techniques and co-ordinated efforts designed to maximize the disruptive impact of chance on

\footnotetext{
${ }^{36}$ Alcock's essay assumed that the future of the New York Game lay in a ten-player field configuration to manage the problem of fair-foul hitting. Henry Chadwick lobbied for this change prior to the 1874 season, but the National Association voted against the proposal. However, in an important mark of baseball's transnational fluidity during the nineteenth century, this tenplayer configuration did become the rule in Cuban baseball from the 1870s to the early 1900s. See Ryczek, Blackguards, pp. 142-53; Echevarria, Pride, pp. 103-4.

${ }^{37}$ Palmer, Sports, pp. 48-50, for an overview of the tour's schedule and finances.

${ }^{38}$ Sportsman, 1 Aug. 1874, p. 8. In barehanded baseball, fielding marked the professional standard. Boston led the National Association with an .850 fielding percentage in 1874, averaging seven errors per game, while the Athletics ranked third, averaging just over seven errors, so combining for sixteen errors at Edgehill, with Boston committing nine and Philadelphia seven, met the professional standard for fielding. Ross Barnes, Harry Shafer, and George Wright of the Red Stockings combined for fifteen infield assists, showing off the standard range factor of the National Association's best infield. Both teams also turned a double play, along with relay throws a crowd favourite among the co-ordinated fielding plays.
} 
batting skills. Moreover, during the first game, won 14 to 11 by the Athletics in ten innings, the outcome turned on an error by Red Stockings leftfielder Andy Leonard, who 'with the sun in his eyes was prevented from making a not very difficult catch', which 'weighed down the scale' for the Athletics during their five-run tenth inning, while 'a splendid catch by [Adrian] Anson at right field', in the bottom of the inning, 'decided the question' for the Athletics. ${ }^{39}$ As thousands of Britons witnessed the New York Game in August, a dialogue began among spectators and journalists concerning the value of this fielding science, its relative weakness or lack of value in cricket, with its emphasis on scientific batting, and whether occasional practice of the New York Game could improve this dimension of British cricket. ${ }^{40}$

British responses to barehanded baseball focused on such 'scientific' elements as its force, its acquired discipline and precision, its co-ordination in relays, and on the transference of its skills from the New York Game to cricket. Among the 'perfect marvels in...fielding', its controlled use of force, from 'whatever position', allowed even in pre-game drills 'no respect for persons, for the ball is thrown as hard as it can be hurled, and yet, though the distance is only a few yards, it is caught like lightning, ${ }^{41}$ The 'height and distance to which the ball was thrown' was 'marvellous', and 'so were many of the catches, especially at short ranges, when the ball seemed to have [the] speed [of] a projectile from a gun'. ${ }^{42}$ The exhibition of these skills in pre-game rituals became one of the tour's major attractions. Before the games at Old Trafford and Lord's, ten minutes or so of 'larking' in drills, during which the Americans 'threw the ball with wonderful strength and precision, fielded very smartly, and never missed a possible catch...impressed the public very favourably' ${ }^{43}$ In addition to the 'precision' of these techniques, 'the judgment and practice necessary' to attain this 'great skill with the ball' involved a measured co-ordination of the forces generated by several players across the field that Britons came to identify as both a distinctive feature of the New York Game's dynamics and its more fundamental moral science. ${ }^{44}$ In its 'rapid fielding', all the throwing was 'full pitch', and 'when the longfields threw up, they threw hard to a man halfway, who passed it on with the same hard low throw', in a co-ordinated relay, 'instead of shying up for the wicket keeper as we do at cricket to take it on the first bound' ${ }^{45}$ This 'discipline' of fielding, 'cultivated with assiduity and zeal', marked the ethos of the New York Game "with less of that individual love of success which makes many an English cricketer concentrate his interest in his own runs, but more of that unselfishness which merges the good of the one in the success of the many'. ${ }^{46}$

${ }^{39}$ Ibid.

${ }^{40}$ See Morning Post (MP) (London), 3 Aug. 1874, p. 4, among many contributions to this dialogue.

${ }^{41}$ Banbury Advertiser (BA), 13 Aug. 1874, p. 3.

${ }^{42}$ DTC, 3 Aug. 1874, p. 2.

${ }^{43}$ Ibid.; ISDN, 8 Aug. 1874, p. 14. One of the American players 'gained hearty cheers by allowing the ball to go over his head, and then catching it behind his back', displaying 'a wonderful judgment of distance'. Daily News (DN) (London), 4 Aug. 1874, p. 7.

${ }^{44}$ Sportsman, 4 Aug. 1874 , p. 3.

${ }^{45}$ LES, 4 Aug. 1874, p. 6.

${ }^{46}$ MP, 3 Aug. 1874, p. 4. 
Unsurprisingly, the dialogue further engaged the issue of whether and how British cricket might benefit from the fielding discipline of the New York Game, an important aspect of ludic diffusion that nevertheless fell far short of any interest in the displacement of cricket by baseball. At Bramall Lane on 15 August, despite 'moderately good' fielding by the Sheffield cricketers, the Americans continued a run of success begun in London, based on a strategy that substituted superior run prevention in the field for scientific batting skill. When the Americans took the field, several 'hard hits were made without scoring...the fielding of the Americans being particularly smart'. After 'such an exhibition of fielding...never before witnessed on Bramall Lane', one reporter observed that 'the institution of a base ball club in Sheffield would do a great deal of good, instructing cricketers in that important element for the success of a match, fielding. ${ }^{47}$

Although the New York Game's fielding science had the greatest impact on British public discourse, becoming a primary motive for the organization of games and baseball clubs in Britain following the tour, its reception in 1874 involved a broader, more complex process of diffusion in which the experience of the tour in performance and print promoted a transnational awareness of the value of both cricket and baseball as distinctively modern mass entertainments. This involved, first, an increasingly informed debate over the extent to which the New York Game comprised a competitive science, comparable to cricket, differentiating it from simple games and justifying an investment of valuable time learning how to watch as well as play it. Despite disclaimers suggesting 'the technical intricacies' of baseball 'are terra incognita to us', British journalists of the 1870s had a quick grasp of sporting matters and used their experience of the tour to foster a knowledgeable debate. ${ }^{48}$ In its batting science, the New York Game 'wasted force' by 'the rule according to which all hits must be made within certain limits' and suffered generally from 'the absence of a wicket to be attacked and defended', lacking 'those pretty cuts, well judged drives, and wary receptions of dangerous balls which are the delight of the spectators at Lord's'. ${ }^{49}$ The arbitrariness of foul lines and three outs per inning enlarged the influence of chance on baseball's complex physics and game dynamics, promoting suspense, excitement, and surprise at the expense of science and certainty. In addition to arbitrary limitations of 'the liberties of the bat', its pitching speed, and the close co-operation of the battery in the New York Game further restricted any display of its batting force to match the mechanistic standard achieved by efficient cricketers. ${ }^{50}$ Although 'the ball might be sent 150 yards, from the rapid way they are delivered and the closeness of the pitcher, the striker has scarcely time to give it the full sweep of a blow', for 'though the bowling is underhand, it is remarkably

${ }^{47}$ SDT, 17 Aug. 1874, p. 4; SI, 17 Aug. 1874, p. 4, describing the Americans' 'slogging' method of cricket batting as 'perhaps more effective than scientific'.

${ }^{48}$ SI, 17 Aug. 1874, p. 4.

${ }^{49}$ SDT, 18 Aug. 1874, p. 8, reprinted from the Saturday Review (London). See also MCLGA, 7 Aug. 1874 , p. 7, complaining that 'the rules appear too sparing of runs, [and] many of the best hits are wasted, as the batsman has to trust to chance where his ball goes'.

${ }^{50}$ The Field, vol. 44, 25 July 1874, p. 100; BA, 13 Aug. 1874, p. 3. 
swift'. ${ }^{51}$ Several observers remarked on the speed of base running - an offensive force absent from cricket - as a countervailing source of pressure on the battery and fielders, capable of turning safe hits and errant throws or missed catches into extra bases and runs. Because this only augmented the influence of risk and chance, or the arbitrary nature of the New York Game, it did not strengthen its scientific claims but added to British appreciation of its tactical and strategic complexity and the 'judgment' required to play it well. During the early moments of the first game at Lord's on 3 August, George Wright hit safely 'then watched his opportunity and ran for the second base' as the pitcher delivered the ball, 'a dangerous experiment...if the catcher can throw the ball to the second baseman in time', but the 'experiment' succeeded, and Ross Barnes then singled Wright home with the game's first run. ${ }^{52}$ The tactical value of 'fleetness of foot' on the bases contributed to a 'general scene of alertness', as 'the game becomes highly interesting when the "ins" have men at more than one base, for the "outs" have then not only to watch the striker, but also his partner, who will "steal" a base' on 'the slightest relaxation in vigilance. ${ }^{53}$

This public debate during August and September offered a favourable assessment of the New York Game as an expression of modern field science and a useful addition to the British seasonal repertoire - less scientific than cricket, and no threat to its popularity, but more 'exciting' to the extent that it allowed 'chance' to influence outcomes on the field. ${ }^{54}$ Although both cricket and baseball required rapid decision-making, the New York Game complicated the calculation of risks by making it situational, dependent on unique, changing field conditions. This raised concerns about the impact of 'excitement' on British crowds ranging from 1,000 to 5,000 spectators - a common attendance figure for National Association games in 1874. Yet the subtraction of 'science' from the art of watching the New York Game, relative to cricket, found compensation in improving displays of 'unselfishness' and sacrifice, a consistent 'playing for the side', in which 'individual prowess is merged in united success, and every one cares more for his fellows than himself. ${ }^{55}$ Viewed in this way, as a constantly changing but morally improving series of events, its greater competitive efficiency turned the New York Game into cricket's democratic superior in the progressive, civilizing functions of modern mass entertainment. Unlike its foreshortened cricket matches, spread over a couple of days, the tour's baseball games lasted a couple of hours. As an appreciative Morning Post reporter observed, 'no time is wasted...in cricket there is so much dawdling that the game is prolonged to an extent prohibitive to men whose time is taken up by business...and year after year men desert the cricket field...because they are unable to give up two days for every match'. In this sense, the New York Game blended field science, principles of organizational

${ }^{51}$ LES, 4 Aug. 1874, p. 6; Leeds Mercury (LeM), 1 Aug. 1874, p. 11.

${ }^{52}$ MP, 4 Aug. 1874, p. 6; Liverpool Mercury (LiM), 5 Aug. 1874, p. 3; DN, 4 Aug. 1874, p. 7, for Boston's batting order on 3 August.

${ }^{53}$ MP, 1 Aug. 1874, p. 6.

${ }^{54}$ MCLGA, 1 Aug. 1874 , p. 6; LES, 4 Aug. 1874, p. 6; MP, 4 Aug. 1874, p. 6; Manchester Times (MT), 8 Aug. 1874, p. 7; FJ, 25 Aug. 1874, p. 3; DN, 28 Aug. 1874, p. 5; SI, 17 Aug. 1874, p. 4.

${ }^{55}$ MP, 3 Aug. 1874 , p. 4; 4 Aug. 1874 , p. 6. 
efficiency, and a democratic ethos in 'a game which has the merits of cricket and the great additional advantage that it takes little time...a benefit [for] all the lovers of exercise in the country'. ${ }^{56}$ However, as Robert Stopford, a Royal Navy admiral and chairman of the Richmond Cricket Club, suggested in a public speech, the major achievement of modern field science, amid 'a century of progress such as the world has never seen', involved not the 'national' choices of cricket or baseball, but the transnational exhibition of 'proficiency' in both. ${ }^{57}$

By the time the Red Stockings and Athletics embarked at Queenstown on 27 August, the 'sensation' of the 1874 Tour had established the New York Game in British public discourse. ${ }^{58}$ In terms of its ludic diffusion, this involved a broad recognition of practical and cultural value. Its unique physics and game dynamics fostered defensive techniques that transferred to cricket. As the tour had revealed the power of defensive run suppression to overcome poor batting discipline, enabling elite baseball players to defeat competent cricketers on their own pitches, the New York Game had demonstrated its practical value as a training exercise for British cricketers. More importantly, the New York Game afforded broader opportunities for the experience of field exercise, its efficiencies adapted to the work discipline of Britons and its field configuration easily modified to suit urban spaces designed for cricket. This British appreciation of baseball in 1874 as a social leveller, in the practical way it could offer exercise and friendly competition to middle- and working-class Britons who lacked the leisure time or fees for cricket clubs, echoed its promotion of 'playing for the side' in British newspapers during the tour. The New York Game thus engaged broader British cultural values related to social class, personal happiness, and public health, confirming the progressive, civilizing influence of baseball on those who watched as well as those who played it. As curiosity about the American tourists turned to enthusiasm for a sporting novelty during the tour's London dates, editorial letters in British newspapers began to reflect a shifting perspective on the New York Game's transatlantic status. Its significance as 'scientific rounders', rendering an unfamiliar American import in British cultural terms, became something closer to cultural appropriation. ${ }^{59}$

\section{V}

Leicester's absence from the tour schedule and its public discourse concerning the New York Game in 1875 make it an unlikely site for Britain's first baseball

\footnotetext{
${ }^{56}$ This is not arguing that baseball had or has a democratic nature, but rather that British perceptions of its democratic qualities, relative to cricket, influenced its ludic diffusion. LeM, 1 Aug. 1874, p. 11; MP, 3 Aug. 1874, p. 4; 4 Aug. 1874, p. 6; LiM, 5 Aug. 1874, p. 3; MT, 8 Aug. 1874, p. 7; BA, 13 Aug. 1874, p. 3; SDT, 18 Aug. 1874, pp. 7, 8.

${ }^{57}$ DN, 10 Aug. 1874, p. 6; MP, 10 Aug. 1874, p. 6.

${ }^{58}$ Western Gazette (Yeovil), 7 Aug. 1874, p. 2; SDT, 27 Aug. 1874, p. 3; Palmer, Sports, p. 50, described the tour as a 'financial failure', its expenses being made up from exhibition games played in the United States, and this has remained the verdict on the whole transnational project.

${ }^{59}$ SL, 21 Jan. 1874, p. 4; MT, 8 Aug. 1874, p. 7, for the New York Game as 'a novelty'. See Echevarria, Pride, p. 76, and Whiting, Wa, pp. 28, 46, for analogous cultural appropriations involving batos in Cuba and yakyu in Japan.
} 
clubs and interclub matches. In July 1875, The Leicester Daily Post reprised the tendentious view of the tour as a 'transatlantic attempt to substitute the schoolboy pastime of rounders for cricket', pronouncing it an 'ignominious failure'. ${ }^{60}$ However, the rapid process of demographic and economic change that transformed Leicester from a domestic manufacturing and market town of 60,000 inhabitants in 1850 into an industrial city of 210,000 in 1900 also shaped the dynamic social environment in which a marginal pastime like the New York Game became attractive. ${ }^{61}$ Only seven months after its triumphal misinterpretation of the 1874 Tour, The Daily Post announced the first performance of 'base ball' in Leicester, with a game scheduled to take place at Victoria Park on Saturday, 19 February $1876 .{ }^{62}$ 'Sides consisting of nine players' signalled the New York Game, explained to The Daily Post's readers in the conventional British fashion as 'scientific rounders'. In a manner that embodied the meaning of the New York Game in Leicester, this first match brought together one of its innovative business entrepreneurs and one of its premiere cricket clubs. As The Daily Post disclosed, Alfred Hamel, the proprietor of one of Leicester's worsted spinning factories and friend of J. D. Harris of Harris and Sons, a major business dynasty, had arranged the match with members of the powerful Victoria Park Cricket Club and would join them to select the sides. ${ }^{63}$ The New York Game's successful diffusion in Leicester during 1876 and 1877 received its impetus from the participation of prominent business leaders, established cricketers, and from a broader group of men and boys attracted to the new field science by the flexibility of baseball's niche in Leicester's recreational subculture.

After the first game, Hamel established the Leicester Base Ball Club (BBC) and began to organize Saturday intraclub matches on the fields at Victoria Park. A short schedule from 19 February to 1 April, when preparations for the cricket season began, culminated in the first interclub match between a nine from the Leicester $\mathrm{BBC}$ and a nine from a new club established by Leicester's formidable Oxford Cricket Club, captained by Henry Walter, the club's best batsman. The style, dynamics, and other qualities of the New York Game played under these circumstances received brief notices in the local press and reflect the now conventional British preoccupations established during the tour. On 11 March, The Leicester Chronicle and Leicestershire Mercury reported of the previous week's 'very successful' matches that 'the

\footnotetext{
${ }^{60}$ LDP, 15 July 1875 , p. 3.

${ }^{61}$ In addition to population growth, Leicester experienced a shift from domestic to factory production in its hosiery and footwear industries and the establishment of new engineering firms linked to the Midlands Railway and to such new path technologies in Leicester as the tramlines built during the 1870s. VCH Leicester, pp. 251-302; Francois Bedarida, Social history of England (2nd edn, New York, NY, 1991), pp. 17-18; J. Harrison, Late Victorian Britain (New York, NY, 1991), 15.

${ }^{62}$ LDP, 19 Feb. 1876, p. 4.

${ }^{63}$ Dinah Freer, 'The dynasty-builders of Victorian Leicester', Transactions of the Leicestershire Archaeological and Historical Society, 53 (1977/1978), pp. 42-54, and Dinah Freer, Business families in Victorian Leicester (Leicester, 1975), for the Harrises and Hamels; Alan Everitt, Landscape and community in England (London, 1985), p. 314, refers to the late Georgian and Victorian eras as an 'apotheosis' of dynastic cohesion for such influential Leicester families as the Harrises.
} 
fielding was very fair all-round on both sides' and noted 'the best catches of the day'. The interest in batting focused on runs and 'tall hits' that confirmed an established athlete's 'cricketing form'. On 15 March, The Leicester Guardian reported on the 'good all-round play' by the Leicester BBC at Victoria Park, focusing on fielding skills in its account of 'brilliant catches'. This reporter made more of the balance between 'fielding and batting' and also introduced some of the New York Game's unique jargon, observing Leicester's first recorded 'home run'. Playing on the arbitrary element of chance made familiar to the British public during the tour, the account described how one side scored five runs in its first inning, "but in their second achieved the glory of a "whitewash", thanks to the sharp fielding of their adversaries'. These descriptions reflect the priorities of 1874, confirming the New York Game's status as a niche pastime capable of generating its own competitive excitement and involving its own particular skills but valuable mainly as preparation for the cricket season and as a school for the improvement of fielding technique among cricketers. ${ }^{64}$

The first interclub match, played on 1 April 1876, suggests the important undercurrents of amateur club baseball and the difficulties of their study. Before it defeated Hamel's nine from the Leicester BBC, 29 to 21, little is recoverable of the Oxford BBC, recruited by members of the Oxford Cricket Club as a subgroup of the club's membership. In the socially fluid style of club baseball in other settings, Henry Walter, the captain of the Oxfords, had participated in Leicester BBC matches in March. The local newspapers printed their most elaborated box score to mark this occasion, recording a full nine innings characterized by the excitingly arbitrary ebb and flow of British baseball expectations. After an inning, Leicester led 8 to 6 , but the clubs were even after two frames. Leicester pulled ahead in the fourth, but Oxford drew even by the end of the sixth, only to surrender the lead again in the top of the seventh. Oxford then exploded for nine runs in the bottom of the seventh, taking a 24 to 17 lead, and Leicester would come no closer than 24 to 21 in the eighth. Defensively, Leicester whitewashed the Oxfords in the third and fourth innings, with the Oxfords holding the Leicesters scoreless in the third, fifth, and sixth. ${ }^{65}$ John Williscroft, recipient of 'a prize ball' from the Oxford Cricket Club in 1875 for the highest bowling average and for all around play, paced both clubs with five runs. ${ }^{66}$

The excitement of this first short season carried over into preparations for its successor. In early December 1876, The Leicester Daily Post reported that the baseball club 'recently formed' by the Oxford Cricket Club had 'commenced play' on the Recreation Ground at Welford Road. This small enclosure in St Mary parish, a south Leicester working-class neighbourhood, became the site of a series of 'scratch matches' from early December to late March 1877, overseen by the club captain Henry Walter and attracting both members

\footnotetext{
${ }^{64}$ LCLM, 11 Mar. 1876, p. 10; 8 Apr. 1876, p. 10; Leicester Guardian (LG), 15 Mar. 1876, p. 5.

${ }^{65}$ Leicester Daily Mercury (LDM), 3 Apr. 1876, p. 3; LCLM, 8 Apr. 1876, p. 10.

${ }^{66}$ Leicester Journal (LJ), 19 Nov. 1875, p. 6.
} 
and 'friends' from the surrounding neighbourhood. ${ }^{67}$ In addition to announcing the new season, The Daily Post's reporter favourably surveyed the organizational work of the previous year, observing that 'several cricket clubs, including St. Mary's South End and N. Corah, Sons, and Cooper, have formed base ball clubs', and that 'other clubs not wish[ing] to take part in the more dangerous game of football will no doubt take a similar step', with the result that 'ere long the game of base ball will become general in Leicester, and the matches will be witnessed by the admirers of cricket with much interest'. ${ }^{68}$ This suggests that a minimum of four baseball clubs played matches in Leicester during the 1876 season, the existence of two of them known only from a passing reference. After the 1877 cricket season, the Oxford Cricket Club 'arranged that [its] base ball club should be continued during the coming winter' and elected 'several nonmembers' of the cricket club as members of the Oxford $\mathrm{BBC} \cdot{ }^{69}$ Nor did the attraction of new members exhaust the baseball club's value - its fielding discipline had begun to affect cricket skills in precisely the way many observers had suggested during the tour. In 1877, the Oxford Cricket Club established a prize for best fielder, first presented by Thomas Richardson to John Freer, both members of its baseball club. ${ }^{70}$

Knowing the ballplayers in Leicester is more straightforward than knowing the clubs, which have left no administrative records and surface only fleetingly in newspaper reports. As a result of the occasional box scores published in 1876 and 1877, when amateur baseball constituted a novelty worth reporting in Leicester, it is possible to identify a group of forty-nine ballplayers, men and boys whose names in census and other records enable a collective social portrait of this ballplaying subculture and a few individual life histories that suggest some of the New York Game's subtle meanings in this setting. ${ }^{71}$ Unsurprisingly, 40 per cent of the ballplayers made their livings from the textile and footwear industries that dominated Leicester's economy and drove its social transformation during the late nineteenth century. However, the social significance of the New York Game lay in its power to attract players from all classes of these industries, bringing together leading capitalists; drapers and hosiery mechanics, trimmers, and warehousemen; yarn factors and clerks; boot finishers, shoe clickers and rivetters, in a shared athletic discipline of the ballfield and its variety of co-ordinated tasks. Moreover, the matches attracted workers from every field of the local economy, including substantial minorities from the building and engineering trades, from the professions, and even a fraction involved in agriculture. The majority of these men had occupations unsuited to the demands of the cricket played by local clubs, and to their fees, but could play in the occasional

${ }^{67}$ LDP, 5 Dec. 1876, p. 4; LDM, 5 Dec. 1876, p. 3; Leicester Chronicle (LC), 9 Dec. 1876, p. 3; LCLM, 24 Mar. 1877, p. 5; 31 Mar. 1877, p. 4. On the limited space for public recreation grounds in Leicester during the second half of the nineteenth century, VCH Leicester, pp. 251-302.

${ }^{68}$ LDP, 5 Dec. 1876 , p. 4.

${ }^{69}$ LDM, 29 Oct. 1877 , p. 3.

${ }^{70}$ LDM, 13 Nov. 1877 , p. 4.

${ }^{71}$ This analysis is based on the names of ballplayers culled from box scores published in LCLM, 11 Mar. 1876, p. 10; 8 Apr. 1876, p. 10; 24 Mar. 1877, p. 5; 31 Mar. 1877, p. 4; LG, 15 Mar. 1876, p. 5. See also LDM, 3 Apr. 1876, p. 3. 
scratch baseball game during Saturday afternoons allowed as half holidays by Leicester's biggest factories. Indeed, a majority of the ballplayers lived in the working-class neighbourhoods of St Mary and St Margaret parishes, the latter site of the innovative textile factory owned by Nathaniel Corah, Sons, and Cooper, a patron of cricket and baseball clubs. The new field science came to Leicester's parks by the same agencies and leadership that had promoted the new natural sciences and related technologies, and had celebrated their civilizing and progressive influences, in its public forums and workplaces.

The New York Game occupied a small niche in Leicester's civic culture, but it served many of the same purposes as other more important symbols and practices in building a local sense of belonging. Its transnational relationship to cricket, firmly established during the tour, facilitated this translation of its significance from one setting to another. Among distinct and sometimes antagonistic social groups, it offered a common discipline and experience, marked by the intimacy of co-ordinated physical performance. Although more than half the ballplayers were born in Leicester, nearly half came from other parts of southern Britain, drawn by the workforce demands of Leicester's growing economy. On fields at Welford Road and Victoria Park, the 'scientific rounders' of the New York Game brought transnational novelty to the process of turning these natives and immigrants into neighbours and Leicestrians. At least a third of the men had school or club experience of cricket, and a third also shared relations of family or friendship with other players in the ballgames. Nearly 60 per cent of the ballplayers were young workers aged eighteen to thirty, though more than a third were household heads aged thirty-one to fifty, while less than half of the group (39 per cent) had children in 1876 and 1877. Although the forming of baseball clubs resulted mainly from local cricketers' ambition to master the New York Game's fielding techniques and powers of run suppression, this diverse group of ballplayers suggests more varied meanings in the experience of 'scientific rounders', the subtle meanings of play in individual lives.

These life histories attest to the New York Game's insinuation into Leicester's social and cultural fabric. Robert Clements played cricket as a member of the St Mary's and Oxford Clubs during the 1870s and joined the Leicester BBC for its first matches in 1876. At thirty-two, Clements was older than most other ballplayers, but few men worked harder to promote the cause of field science and outdoor recreation in Leicester. In 1873, Clements served as St Mary's Club representative to the first Leicester and Leicestershire Cricket Association, an organization formed to mobilize cricket interests on a county scale, its early sessions addressing such major obstacles as the lack of public space for cricket in Leicester and the danger to players from cattle grazing in Victoria Park during matches. Clements became the Association's secretary, receiving vocal support from Henry Walter, a fellow St Mary's cricketer with whom Clements played baseball for the Leicester Club. As the causes of public health and exercise drew the New York Game into Leicester's civic culture, the Clements family sporting goods business formed part of the infrastructure that supported its cricket and baseball clubs. J. Clements \& Sons owned the Cricket and British Sport Depot in St Margaret parish, another significant local company vital to 
the diffusion of the New York Game. Joseph Clements and his sons Robert and William managed a complex business that employed ten to fifteen woodturners and their assistants at multiple properties around the city, including a sawmill and retail emporia for the company's finished bats. Robert oversaw the Sport Depot, opened in 1875, and his experience of 'scientific rounders' during the following year thus brought the meanings of cricket and baseball into close relationship with those of family and friendship, business and leisure, private interest and principles of public health and civic duty. ${ }^{72}$

The friendly and familial meanings of baseball, as well as their imbrication in Leicester's civic culture, manifest in slightly different form in the experience of Thomas Pickering, an orphan whose affluent parents left Thomas and his sister an independent 'income derived from the interest of money on land'. On 24 March 1877, Thomas played in the Oxford Club's scratch matches at Welford Road. However, like such other occasional ballplayers as Joseph Collier, Arthur Gill, and George Howe, all members of the Leicester BBC in 1876, Thomas's athletic reputation reflected his captaincy of the Leicester Athletic Society's footballers, where he had met Collier, Gill, and Howe. During his twenties, these competitive experiences translated readily into civic and political identities. An obituary published after his early death in 1886 described Pickering as 'well known in Leicester' for his captaincy in the Leicestershire Volunteer Infantry and as an officer of the Leicestershire Rifle Association. This relationship between athletic experience and civic activism clearly motivated Thomas's decision to join the consortium backing the Leicester Cricket Ground Company, formed in 1877 only two months before Thomas joined the Oxford Club's ballgames. This powerful syndicate included Alfred Hamel, founder of the Leicester BBC, his influential relative John Harris, the industrial dynast and participant in the first interclub baseball match, and Thomas Paget, a banker and former member of parliament for Leicestershire. The company purchased fifteen acres of land in Saffron Hill 'for cricket, bowls, and other outdoor sports', bringing $£ 40,000$ of private capital to bear on the public problem of limited space and building a likely venue for the new Leicester and Leicestershire Cricket Association. Pickering's football teammate from the Leicester Athletic Society and sometime ballplayer, Joseph Collier, served as a 'provisional director' of the new field, opened in 1878 and now known as Grace Road Ground, home of the Leicestershire Cricket Club. ${ }^{73}$

\section{VI}

By the 1870s, cricket in the United Kingdom and baseball in the United States had assumed an institutional form and ideological significance, as modern

${ }^{72}$ LC, 25 Jan. 1873, p. 8; 26 Sept. 1874, p. 7; LDP, 13 Mar. 1875, p. 8; 31 July 1875, p. 8; 4 Aug. 1877, p. 8; The National Archives, UK (TNA): Census returns of England and Wales (CREW), 1871, RG10/3288, 9/12 (Joseph Clements); 1881, RG11/3157, 5/3 (Robert Clements); 3177, 87/4 (William Clements); Commercial and general directory and red book of Leicester (Leicester, 1875), p. 94.

73 TNA: CREW, 1881, RG11/3170, 32/17; LG, 15 Mar. 1876, p. 5; LC, 3 Mar. 1877, p. 9; LCLM, 8 Apr. 1876, p. 10; 31 Mar. 1877, p. 4; LDM, 1 Mar. 1879, p. 6; LJ, 31 Oct. 1879, p. 8; LJ, 12 Feb. 1886, p. 5; VCH Leicester, pp. 415-20. 
sports, that reduced the competitive 'chance' of their displacement in popularity by any rival expression of 'field science'. However, a substantial body of evidence points to the diffusion of the New York Game, an early form of modern baseball, from the United States to the United Kingdom between 1871 and 1877, an expression of a transatlantic technological transfer easy to overlook in an era of vociferous nationalisms. This complex process involved transitions from print to performance, first in 1871, courtesy of the USS Franklin's international crew, then more substantially from 1874 to 1877 , as a result of the National Association Tour and the formation of the first British clubs. As a transnational process, successful diffusion depended on the identification of a shared language and the establishment of a discourse, derived in this instance from common assumptions about the value of science, its relationship to the public good, and its practical application to a wide range of human activities for the purposes of moral improvement and social utility. During the 1870 s and early 1880s, this broad public discourse joined the New York Game, and 'field science' more generally, to the early history of applied electrical power in Britain, a popular enthusiasm for both being expressed in the shared terms of a common language. In Leicester, the promotion of these new corporal and machine technologies radiated from its local companies, serving as relational nodes of transfer, a contingent prelude to the systemic technological momentum of the 1890 s. $^{74}$

Stereotypes of the 1874 Tour as a failure have focused on its financial aspects and a nationalist standard of success, based mainly on American assumptions, missing the important historical dynamics involved in a dual process of transatlantic diffusion. Baseball crossed the Atlantic first from the United Kingdom to its American colonies during the eighteenth century as a popular game played in many different ways. ${ }^{75}$ It returned from the United States to the United Kingdom during the 1870 s as a modern sport, the New York Game, standardized in rules, systematic and quantified in records, rationalized and uniform in techniques and performance, like other components of Anglo-American technology transfer during the 1870s. The British perspective on the 1874 Tour focused on the New York Game's credentials as an expression of the new field science, a shorthand for the traditional field games, exemplified by cricket, which modern techniques had elevated to the status of science - laboratories of athletic skill devoid of chance. This transnational perspective never considered the substitution of baseball for cricket in the United Kingdom. After the tour's conclusion, a public consensus affirmed the New York Game's value, particularly its run suppressing defensive science, as a progressive, civilizing manifestation of field science, comparable if not equal to cricket. Indeed, British admiration sometimes ascended to claims

\footnotetext{
${ }^{74}$ Hughes, Networks, pp. 140-74. Civic promotion closely followed entrepreneurial initiative. See, for example, $L J, 26$ Jan. 1883, p. 1, for 'Science Lectures for the People' at Leicester's Temperance Hall in 1883, less than a month after the electrification of St Margaret's Works, including 'The Dynamo Machine, Electric Lighting, and the Transmission of Power'.

${ }^{75}$ Block, Baseball, pp. 22-31; John Thorn, Baseball in the Garden of Eden (New York, NY, 2011), pp. 25-104.
} 
of possession, based on the New York Game's resemblance to various forms of British protoball.

Diffusion moved from discourse and observation to performance in around eighteen months, establishing the New York Game as a seasonal niche pastime. The scale of this change is difficult to measure because baseball clubs formed within cricket clubs, reflecting beliefs about the value of its defensive discipline for cricketers. The establishment of baseball clubs in Leicester in 1876 and 1877 confirmed British assessments of the tour but also generated new meanings as the experience of baseball and cricket became a familiar aspect of social life in an environment undergoing demographic and economic transformation. Nathaniel Corah, Sons, and Cooper, organizers of one of the first baseball clubs, opened the doors of St Margaret's Works to thousands of Leicestrians between 29 December 1882 and 1 January 1883, following its electrification, in a series of inclusive celebrations, bringing 'the beneficence of brilliant light' to scenes of singing, dancing, and general sociability. The social experience of new mechanical technology involved the inter-relationship of the company and civic corporation, families and neighbourhoods. ${ }^{76}$ In a similar way, Leicester's companies promoted athletic clubs as a boon to business, while its best cricketers understood the strategic introduction of baseball as part of cricket's pre-season training regimen. However, the process of diffusion transcended narrow interests. As the histories of Leicester's local clubs and individual ballplayers suggest, the domestication of the New York Game in Britain, and the social meanings of field science more generally, inflected symbols and relationships across scales and registers, bringing transnational significance to a process of social change experienced in terms of civic culture, neighbourhood, family, even the local landscape. Although these clubs did not coalesce into a league during the 1870s, their numbers and perseverance suggest a familiarity that helps to explain the successful establishment of professional baseball leagues in Britain during the early 1890s. ${ }^{77}$

Acknowledgements. A portion of this research was presented to the Symposium on Baseball and American Culture at the National Baseball Hall of Fame in Cooperstown, NY, in May 2019. I thank all the participants for their comments and suggestions. Michael Adas, Michael Braddick, Richard Doyle, and Greg Eghigian read and commented insightfully on early drafts of the article. Mark Dyreson and the Penn State Center for the Study of Sports in Society have been a constant source of advice and encouragement. I also thank the anonymous reviewers at the Historical Journal for their generous critical response to a trespasser in the modern field.

\footnotetext{
${ }^{76}$ A reporter estimated a crowd exceeding 1,000 revellers on 29 December -300 civic leaders, 800 to 850 employees and spouses; an unspecified but 'numerous gathering' of employees on 30 December; and on 1 January more than 1,000 'poor people' over the age of seventy for tea, singing, and supper 'beneath the rays of this new world electric light'. LCLM, 6 Jan. 1883, p. 6.

${ }^{77}$ See Horrall, Culture, pp. 108-13; Josh Chetwynd, Baseball in Europe (Jefferson, NC, 2008), pp. 8990; Joe Gray, What about the Villa? (Ross-on-Wye, 2010), pp. 17-20, 137-46.
}

Cite this article: Beaver DC (2022). Baseball, Modernity, and Science Discourse in British Popular Culture, 1871-1883. The Historical Journal 65, 1310-1332. https://doi.org/10.1017/ S0018246X21000704 